\title{
Microglia Are Irrelevant for Neuronal Degeneration and Axon Regeneration after Acute Injury
}

\author{
DAlexander M. Hilla, Heike Diekmann, and Dietmar Fischer \\ Division of Experimental Neurology, Department of Neurology Medical Faculty, Heinrich-Heine-University, 40225 Düsseldorf, Germany
}

The role of microglia in degenerative and regenerative processes after damage of the nervous system remains ambiguous, partially due to the paucity of appropriate investigative methods. Here, we show that treatment with the pharmacological colony stimulating factor 1 receptor inhibitor PLX5622 specifically eliminated microglia in murine retinae and optic nerves with high efficiency. Interestingly, time course and extent of retinal ganglion cell (RGC) degeneration after optic nerve crush remained unaffected upon microglia depletion, although remnants of prelabeled apoptotic RGCs were not cleared from the retina in these animals. In addition, microglia depletion neither affected the induction of regeneration associated genes upon optic nerve injury nor the increased regenerative potential of RGCs upon lens injury (LI). However, although the repopulation of the optic nerve lesion site by astrocytes was significantly delayed upon microglia depletion, spontaneous and LI-induced axon regeneration were unaffected by PLX5622 treatment or peripheral macrophage depletion by clodronate liposome treatment. Only concurrent double depletion of microglia and infiltrated macrophages slightly, but significantly, compromised optic nerve regeneration. Therefore, microglia are not essentially involved in RGC degeneration or axonal regeneration after acute CNS injury.

Key words: apoptosis; axon regeneration; lens injury; microglia; neuroprotection; optic nerve; retina

Significance Statement

The roles of microglia, the phagocytosing cells of the CNS, and invading macrophages in degenerative and regenerative processes after injury are still controversial and insufficiently characterized. Here, we show that application of a CSF1R inhibitor eliminated virtually all microglia from the visual system, whereas macrophages were spared. Specific microglia depletion impaired the removal of dead labeled retinal ganglion cells after optic nerve crush, but remarkable had no influence on their degeneration. Similarly, optic nerve regeneration was completely unaffected, although repopulation of the lesion site by astrocytes was delayed significantly. Therefore, contrary to previous reports, this experimental approach revealed that microglia seemingly neither promote nor inhibit neuronal degeneration or axonal regrowth within the injured visual system.

\section{Introduction}

Under physiological conditions, microglial cells constantly scan their microenvironment in the central nervous system (CNS) for subtle alterations (Nimmerjahn et al., 2005). Upon sensing injury or disease, microglia become activated, releasing cytokines and neurotrophic factors and phagocytosing cellular debris (Kreutzberg, 1996; Davalos et al., 2005). It is, however, still unclear

Received March 1, 2017; revised March 29, 2017; accepted April 26, 2017.

Author contributions: A.M.H. and D.F. designed research; A.M.H. and D.F. performed research; A.M.H. and D.F. analyzed data; A.M.H., H.D., and D.F. wrote the paper.

This work was supported by the German Research Foundation. We thank Plexxikon for providing PLX5622 chow and Anastasia Andreadaki and Marcel Kohlhaas for technical support.

The authors declare no competing financial interests.

Correspondence should be addressed to Dietmar Fischer, Ph.D., Division of Experimental Neurology, Medical

Faculty, Heinrich-Heine-University Düsseldorf, Merowingerplatz 1a, 40225 Düsseldorf, Germany. E-mail: dietmar.fischer@uni-duesseldorf.de.

DOI:10.1523/JNEUROSCI.0584-17.2017

Copyright $\odot 2017$ the authors $\quad 0270-6474 / 17 / 376113-12 \$ 15.00 / 0$ whether the overall effect of microglial activation is beneficial or detrimental for the recovery from an insult (Czeh et al., 2011; Jin and Yamashita, 2016). Secretion of neurotrophic factors and removal of potentially deleterious debris by activated microglia are reportedly neuroprotective and promote regeneration of severed axons (Kreutzberg, 1996; Streit, 2002; Hanisch and Kettenmann, 2007; Chen et al., 2012; Rice et al., 2015). Conversely, nonclearance of inhibitory molecules might stall axonal growth, as described for spinal cord lesion sites (Kitayama et al., 2011). Moreover, the release of proinflammatory cytokines might convey neurotoxicity to injured and healthy neurons in the vicinity of an insult (Mey and Thanos, 1993; Levkovitch-Verbin et al., 2006; Bosco et al., 2008).

In addition to their potentially conflicting functions, exploration of the specific role(s) of microglia in diseases and upon physical injury has been hampered by the paucity of experimental approaches to distinguish microglia and invading monocytes/ macrophages reliably (Prinz and Priller, 2014). For instance, minocycline, which attenuates microglia activation, also affects 
other cells such as macrophages and T cells (Hellwig et al., 2013) and might even be directly neuroprotective (Jiao et al., 2014). Currently available genetic models for conditional microglia depletion have also limitations because they mostly lack microglial specificity or lead to an activation of microglia and/or astrocytes (Parkhurst et al., 2013; Bruttger et al., 2015; Waisman et al., 2015). Only recently a pharmacologic approach was developed to deplete microglia specifically based on inhibition of the colony stimulating factor 1 receptor (CSF1R) (Elmore et al., 2014). Less than $1 \%$ of microglia were still detectable in brains of mice on a constant diet of the CSF1R inhibitors PLX3397 or PLX5622, whereas peripheral macrophages and other immune cells and overall brain morphology remained unaffected (Elmore et al., 2014; Dagher et al., 2015). Therefore, this method provides an unprecedented opportunity to elucidate the specific contribution of microglia to neuronal survival and axonal regeneration.

Adult retinal ganglion cells (RGCs) normally fail to regenerate axons upon optic nerve injury and eventually undergo apoptotic cell death (Diekmann and Fischer, 2013). At the same time, microglia in the retina and in the injured nerve become activated and, together with macrophages infiltrating the nerve, phagocytose cellular and axonal debris (Mey and Thanos, 1993; Bennett et al., 2016). In addition, these cells are supposedly involved in glial scar formation at the injury site, which inhibits CNS axon regeneration (Fischer, 2012; Prinz and Priller, 2014). However, the specific contribution of microglia to events triggered by nerve injury is still unknown. For example, it is still unclear whether activated microglia promote neurotoxicity or RGC survival or if they are just responsible for the clearing of cellular remnants in the retina. Similarly, it is as yet unknown whether cytokine and/or neurotrophic factor secretion by microglia might support or obstruct optic nerve regeneration. In addition, the role of peripheral macrophages in these processes is controversial, too (Fischer, 2008; Hauk et al., 2008).

The current study demonstrates that mice on a PLX5622 diet have almost no microglia in their retinae and optic nerves, which compromised clearance of apoptotic RGCs and delayed the repopulation of the lesion site by astrocytes after optic nerve crush (ONC). However, time course and extent of RGC degeneration remained unchanged. Moreover, the outcome of normal and lens injury (LI)-induced axon regeneration (Fischer et al., 2000; Yin et al., 2003) was unaffected by microglia and peripheral macrophage depletion. Only double depletion of microglia and infiltrated macrophages slightly, but significantly, compromised axon regeneration. Therefore, despite their role on phagocytosis and recruitment of astrocytes to the lesion site, microglia are not fundamentally involved in neuronal degeneration or axonal regeneration after acute optic nerve injury.

\section{Materials and Methods}

Animal experiments. C57BL/6 male and female mice (2-3 months old) were used for all experiments. Mice were housed under the same conditions for at least $10 \mathrm{~d}$ before being used in experiments and maintained on a $12 \mathrm{~h}$ light/dark cycle with ad libitum access to food and water. All experimental procedures were approved by the local animal care committee (LANUV Recklinghausen) and conducted in compliance with federal and state guidelines for animal experiments in Germany.

Microglia depletion. To deplete microglia in vivo, mice were given the CSF1R inhibitor PLX5622 (Plexxikon) mixed into AIN-76A standard chow (Research Diets) at $1200 \mathrm{ppm}$. Respective controls received AIN$76 \mathrm{~A}$ standard chow. Mice were fed for at least $21 \mathrm{~d}$ before further experimental processing to ensure maximum microglia depletion.

Monocyte/macrophage depletion. The use of clodronate liposomes is a widely accepted approach to deplete monocytes/macrophages selectively in vivo (van Rooijen et al., 1996). Mice were injected intraperitoneally with $20 \mu \mathrm{l}$ of clodronate liposomes (Clodronate Liposomes) per gram bodyweight $2 \mathrm{~d}$ before ONC and then every other day until the end of the experiment.

Surgical procedures. Mice were anesthetized by intraperitoneal injections of ketamine $(120 \mathrm{mg} / \mathrm{kg})$ and xylazine $(16 \mathrm{mg} / \mathrm{kg})$. The left optic nerve was intraorbitally crushed $1 \mathrm{~mm}$ behind the eyeball for $10 \mathrm{~s}$ using jeweler's forceps (Hermle), as described previously (Leibinger et al., 2009). The lens capsule was retrolentally punctured using a glass capillary immediately after ONC to increase the regenerative capacity of injured RGCs (Fischer et al., 2001). Two days before tissue isolation, regenerating axons were labeled by intravitreal injection of $2 \mu \mathrm{l}$ of Alexa Flour 555conjugated cholera toxin $\beta$ subunit (0.5\% CTB, in PBS; Invitrogen).

Immunohistochemistry. Mice were anesthetized and intracardially perfused with cold PBS followed by $4 \%$ paraformaldehyde (PFA) in PBS. Eyes and attached optic nerves were removed from connective tissue, postfixed overnight in $4 \% \mathrm{PFA} / \mathrm{PBS}$ at $4^{\circ} \mathrm{C}$, and subsequently transferred to $30 \%$ sucrose for at least $4 \mathrm{~h}$. Spleens were postfixed for $2 \mathrm{~d}$ and incubated in 30\% sucrose for at least $2 \mathrm{~d}$. Tissues were then embedded in KP-cryo compound (Klinipath) and longitudinal sections (14 $\mu \mathrm{m})$ were cut on a CM3050 S cryostat (Leica Biosystems), thaw mounted onto charged glass slides (Superfrost Plus; VWR), and stored at $-20^{\circ} \mathrm{C}$ until further use.

Retinal whole mounts were prepared without prior perfusion, fixed in $4 \%$ PFA/PBS for $30 \mathrm{~min}$ at room temperature, and then incubated in $2 \%$ Triton X-100/PBS for $1 \mathrm{~h}$ to improve antibody penetration. RGCs in flat-mounted retinae and eye sections were specifically visualized using a monoclonal antibody against $\beta$ III-tubulin (1:1000; RRID: AB_2313773; Biolegend). Microglia and macrophages were identified with monoclonal antibodies against Ibal (1:1000; RRID: AB_839504; Wako) or CD11b (1:500; RRID: AB_321292; Bio-Rad). On optic nerve sections, nuclei of mature oligodendrocytes and oligodendrocyte precursor cells (OPCs) were stained with a polyclonal antibody against oligodendrocyte lineage transcription factor 2 (Olig2; 1:1000; RRID: AB_10141047; Millipore Bioscience Research Reagents) and astrocytes were detected using a polyclonal antibody against glial fibrillary acidic protein (GFAP; 1:25; RRID: AB_641021; Santa Cruz Biotechnology). Secondary antibodies included donkey-anti-mouse, anti-goat, and anti-rabbit IgG antibodies conjugated to Alexa Fluor 405, 488, or 594, respectively (all 1:1000; Invitrogen). Sections and whole-mounts were coverslipped with Mowiol and analyzed using either fluorescent (Axio Observer.D1; Zeiss) or confocal laser scanning (SP8; Leica) microscopes.

Retrograde staining of RGCs and retinal microglia. The left optic nerve was exposed and transected. A small crystal of 4-(4-(Didecylamino)styryl)- $N$ methylpyridinium iodide (4-Di-10-ASP; Thermo Fisher Scientific) was placed onto the proximal nerve stump. Retinal whole mounts were prepared $14 \mathrm{~d}$ thereafter and processed for immunohistochemistry (see above). The permeabilization step was performed with $0.05 \%$ Triton X-100/PBS to avoid extraction of the membrane-associated dye.

$R N A$ isolation and quantitative RT-PCR. Total RNA was isolated from retinae using the RNeasy Mini kit (Qiagen) according to the manufacturer's protocol. Retina-derived RNA was reverse transcribed using Superscript II (Invitrogen). Expression analysis of Gap43, Galanin, Sprrla, Csf1r, and Gapdh was performed using SYBR Green PCR Master Mix (Applied Biosystems) and QuantiTect primers (Mm_Gap43_1_SG, Mm_Gal_1_SG, Mm_Sprr1a_2_SG, Mm_Csf1r_1_SG, and Mm_Gapdh_3_SG; Qiagen) on the Applied Biosystems 7500 real-time PCR system. Retina-derived cDNA was amplified during 45 cycles according to the manufacturer's protocol. All reactions were performed in duplicate for at least three independent runs. The specificity of the PCR products was verified with the dissociation curve analysis feature of the Applied Biosystems 7500 software.

Quantification of axons, astrocytes, and oligodendrocyte lineage cells in the optic nerve. Axon regeneration was quantified as described previously (Leibinger et al., 2012; Leibinger et al., 2013a). In brief, photographs of at least five longitudinal optic nerve sections per animal were taken under $200 \times$ magnification using a fluorescent microscope (Axio Observer.D1; Zeiss). Numbers of CTB-labeled axons extending $0.5,1,1.5,2,2.5$, and 3 $\mathrm{mm}$ from the injury site were quantified and normalized to the width of 
A

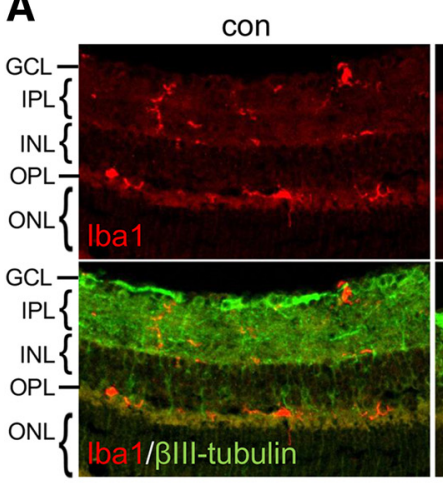

B

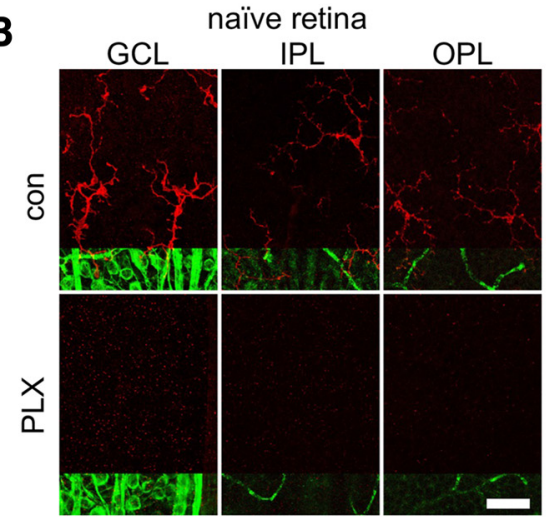

C

naïve retina

7 d PLX
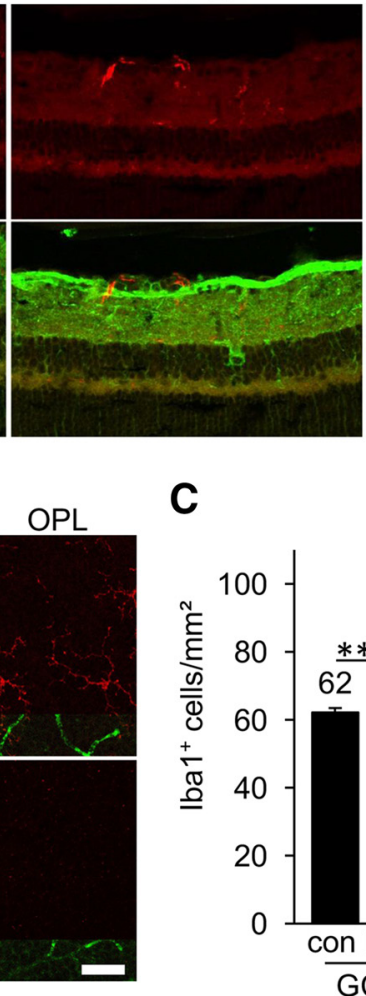

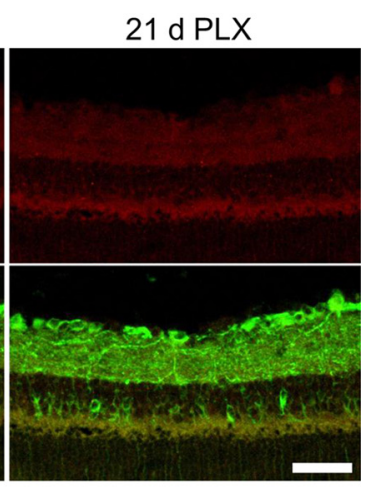

naïve retina
D

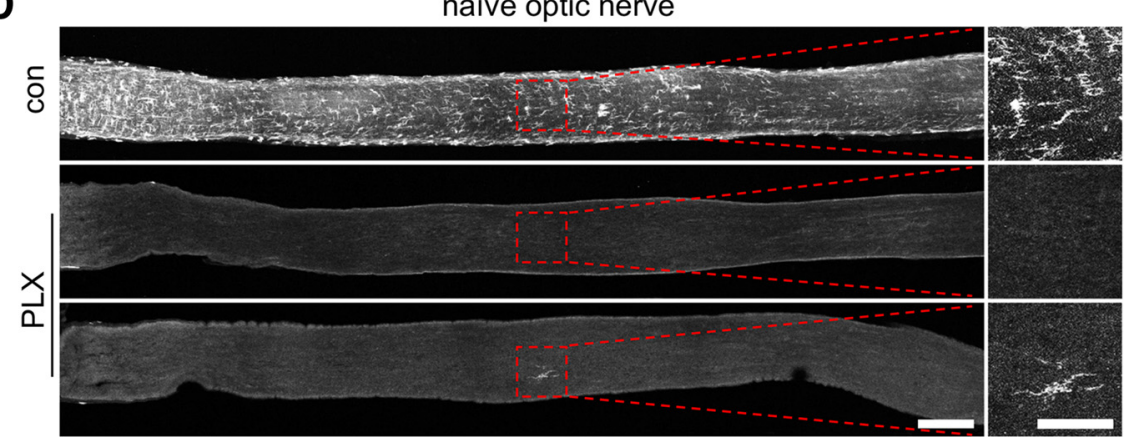

Figure 1. Depletion of microglia in retinae and optic nerves of naive mice via pharmacologic inhibition of CSF1R. A, Iba1positive cells (red) were identified in the $\mathrm{GCL}$, the IPL, and the OPL on retinal cross-sections of untreated control mice (con). After $7 \mathrm{~d}$ on a constant PLX5622 diet (PLX), fewer stained cells were detected, whereas no positive signal was observed after $21 \mathrm{~d}$. For spatial orientation, immunostaining of $\beta$ Ill-tubulin (green) was used to label RGCs and their axons in the $\mathrm{GCL}$, whereas RGC dendrites were detected in the IPL. INL, Inner nuclear layer; ONL, outer nuclear layer. Scale bar, $25 \mu \mathrm{m}$. $\boldsymbol{B}$, Representative confocal pictures of flat-mounted mouse retinae showing lba1-positive ramified microglia (red) in the GCL, IPL, and OPL of naive retinae. Coimmunostaining for $\beta$ III-tubulin (green) was used to detect RGCs and their axons in the GCL and blood vessels in the IPL and $O P L$, respectively. No Iba1-positive cells were detected in animals that had been before on a PLX diet for $21 \mathrm{~d}$. Scale bar, $25 \mu \mathrm{m}$. $\boldsymbol{C}$, Quantification of Iba1-positive cells in respective layers (GCL, IPL, and OPL) of flat-mounted retinae from control-and PLX-treated mice as shown in $\boldsymbol{B}$. Mean microglia numbers per square millimeter are depicted above the respective columns. No microglia were detected upon $21 \mathrm{~d}$ long PLX treatment. Treatment effects: ${ }^{* * *} p<0.001$ for 6 mice per experimental group (1-way ANOVA with Holm-Sidak post hoc test). D, Iba1-stained microglial cells were detected throughout optic nerves of untreated control mice (con), but depleted upon PLX treatment. A rare example of a remaining single lba1-positive cell (bottom PLX-treated optic nerve) is presented to substantiate that lba1 staining still works in PLX-treated animals. Dashed boxes indicate areas magnified in the respective photographs to the right. Scale bars, $200 \mu \mathrm{m}$ in overview and $100 \mu \mathrm{m}$ in respective magnifications.

the optic nerve at the respective measuring point. Experimental groups included five to eight mice.

GFAP fluorescence intensity was determined by measuring the mean gray value of three randomly selected $150 \times 150 \mu \mathrm{m}$ sectors per optic nerve section using ImageJ software. The data from five mice per experimental group were evaluated and presented as mean GFAP intensity \pm SEM. Olig2-positive nuclei were counted manually within three ran- domly selected $150 \times 150 \mu \mathrm{m}$ sectors per optic nerve section and are presented as means per square millimeter.

Measurement of lesion size and mean GFAP fluorescence intensity. Mice were perfused either 10 or $21 \mathrm{~d}$ after ONC and optic nerves processed as described above to visualize GFAP-positive astrocytes. Cell nuclei were stained by incubation with 6-diamidino-2phenylindol (DAPI) for $30 \mathrm{~s}$. Areas with reduced GFAP staining were measured using Image J software and divided by the width of the optic nerve at the lesion site to assess the relative area size. In addition, mean gray values of a $500 \times 150 \mu \mathrm{m}$ sector centered at the lesion site were determined for the quantification of GFAP fluorescence intensity. Data were evaluated for five mice per experimental group on four sections each and are presented as mean GFAP intensity \pm SEM.

Quantification of RGCs in retinal whole mounts. Immunostained flat-mounted retinae were virtually divided into four quadrants and four to five discontinuous photographs were taken in each quadrant using a fluorescent microscope (400×, Axio Observer.D1; Zeiss), proceeding from the retinal center to the periphery. The number of $\beta$ III-tubulin-positive RGCs was determined and normalized to 1 $\mathrm{mm}^{2}$. Values were averaged per retina and across all similarly treated animals (four to 11 per experimental group) to obtain group means \pm SEM.

Quantification of Iba1-positive cells in flatmounted retinae. Flat-mounted retinae were costained with antibodies against $\beta$ III-tubulin and Ibal. Three $z$-stacks (30-50 sections of $1.038 \mu \mathrm{m})$ were recorded from the ganglion cell layer (GCL) through to the outer plexiform layer (OPL) in each retinal quadrant using a confocal laser scanning microscope (200×, SP8; Leica). Because mice were not perfused before retina preparation, blood vessels were stained by the anti-mouse secondary antibody upon RGC labeling with $\beta$ III-tubulin mouse monoclonal antibody (1:1000; Biolegend), which facilitated distinction of the different retinal layers: the ganglion cell layer (GCL, top $4-8$ sections) was identified by $\beta$ III-tubulinpositive RGCs (top 4-8 sections), whereas the inner plexiform layer (IPL; middle 15-25 sections) and OPL (bottom 8-16 sections) were characterized by unspecifically stained blood vessels. Iba1-positive cells were quantified per layer in each $z$-stack and normalized to $1 \mathrm{~mm}^{2}$. Values were averaged per retina and across all similarly treated animals (four to six per experimental group) to obtain group means \pm SEM.

Dissociated retinal cell cultures. Five days before tissue isolation, mice were subjected to $\mathrm{ONC}+\mathrm{LI}$ (in vivo priming). Retinal cultures were prepared as described previously (Grozdanov et al., 2010; Leibinger et al., 2009; Leibinger et al., 2013b). In brief, retinae were dissected rapidly and incubated in digestion solution containing papain $(10 \mathrm{U} / \mathrm{ml}$; Worthington) and L-cysteine $(0.2 \mathrm{mg} / \mathrm{ml}$; Sigma-Aldrich) in Dulbecco's modified Eagle medium (DMEM; Invitrogen) at $37^{\circ} \mathrm{C}$ for $30 \mathrm{~min}$. After rinsing twice with DMEM, retinae were triturated in $2.5 \mathrm{ml}$ of DMEM containing B27 supplement (1:50; Invitrogen) and penicillin/streptomycin (200 U/ml; 
Biochrom). Dissociated cells were passed through a cell strainer (40 $\mu \mathrm{m}$; BD Falcon) and $300 \mu \mathrm{l}$ of cell suspension was added into each well of poly-D-lysine-coated $(0.1 \mathrm{mg} / \mathrm{ml}$, molecular weight between 70,000 and 150,000 Da; Sigma-Aldrich) 4-well plates (Nunc). Retinal cells were cultured for $24 \mathrm{~h}$ and fixed in $4 \%$ PFA/PBS. RGCs with regenerated neurites were photographed using a fluorescent microscope (200× magnification, Axio Observer.D1; Zeiss) and neurite length was determined using ImageJ software. In addition, the total number of $\beta$ IIItubulin-positive RGCs with an intact nucleus (DAPI stain) per well was quantified to reveal potential neurotoxic effects. Average neurite length per RGC was calculated by dividing the sum of neurite length by the total number of RGCs per well. Data represent means \pm SEM of three to six independent experiments, each with four replicate wells per treatment.

Statistical analysis. Significances of intergroup differences were evaluated using either Student's $t$ test or one-way and two-way ANOVA, followed by Holm-Sidak post hoc test using GraphPad Prism software.

\section{Results}

Efficient depletion of microglia in

retinae and optic nerves

Chow-mediated application of the CSF1R inhibitor PLX5622 was shown previously to deplete microglia efficiently in mouse brains without affecting peripheral populations of monocytes/macrophages (Elmore et al., 2014; Elmore et al., 2015; Waisman et al., 2015). Because retinae and optic nerves were not analyzed in these studies, we first addressed this aspect by processing these tissues from mice on normal or PLX5622 diet for Iba1-positive microglia and potentially peripheral monocytes/macrophages. As described previously, Iba1positive cells were detected in the GCL, IPL, and OPL (Fig. 1A-C) (Wang et al., 2016) and the entire optic nerves (Fig. 1D) of untreated mice. In comparison, respective cells were undetectable in the entire retina upon 3 weeks of PLX5622 treatment, whereas a 1-week treatment depleted cells only incompletely (Fig. $1 A-C$ ). Like retinae, optic nerves were also devoid of Iba1-positive cells (Fig. 1D), although single-stained cells were very occasionally found, representing either nondepleted microglia or infiltrated macrophages. As reported previously, monocytes/macrophages in peripheral tissues such as the spleen were completely unaffected by PLX5622 treatment, but efficiently depleted upon injection of clodronate liposomes (Fig. 2A) (van Rooijen et al., 1996). In addition, we detected no general reactive gliosis of astrocytes, determined by the mean gray value of GFAP intensity, upon 3 weeks of PLX5622 treatment (Fig. 2 B, C). Furthermore, cell numbers of oligodendrocyte lineage cells, quantified by Olig2 staining, remained unchanged in optic nerves of PLX5622-treated mice (Fig. 2D,E). Therefore, the PLX5622 diet efficiently and specifically depleted microglia from retinae and optic nerves, whereas peripheral macrophages were diminished selectively upon clodronate lipo-
A con naïve spleen

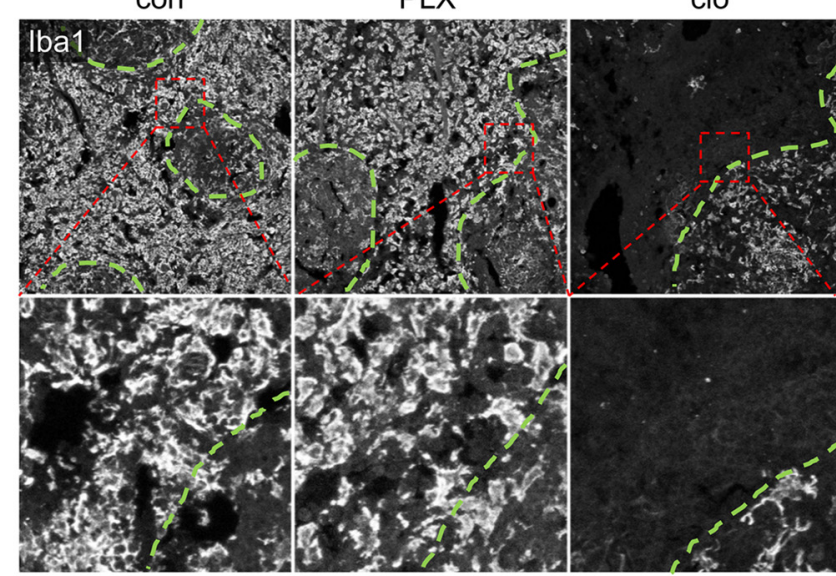

B

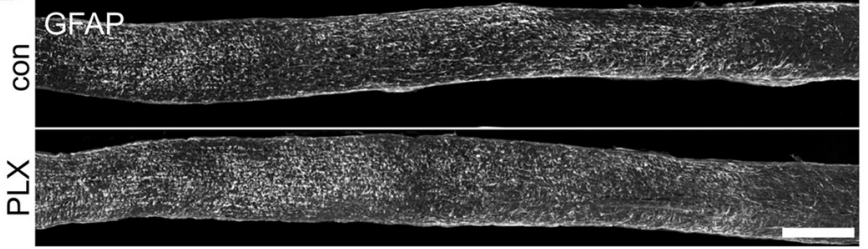

naïve optic nerve

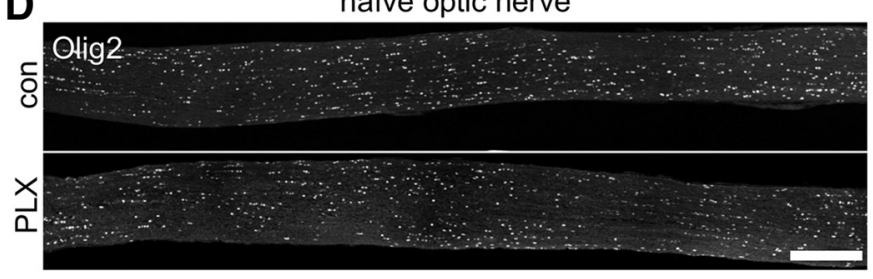

naïve optic nerve

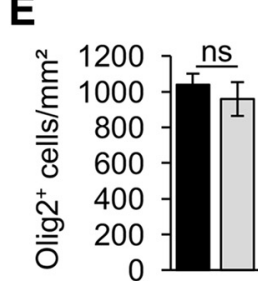

Figure 2. PLX5622 treatment is specific for microglia. $A$, Iba1 immunostaining was unchanged on thin sections of spleen isolated from mice on either 3-week control (con) or PLX5622 (PLX) diet, indicating that peripheral monocytes/macrophages were unaffected by this treatment. In comparison, the majority of monocytes/macrophages were eliminated upon injection of clodroaccessibility by liposomes. Cotreatment with PLX and clodronate liposomes (PLX+clo) did not further reduce numbers of Iba1列 ( (a) 2-positive cell nuclei on optic nerve sections as depicted in $\boldsymbol{D}$. Cell nuclei were quantified in three randomly selected $150 \times 150 \mu \mathrm{m}$ sectors per nerve section and data are presented as means per square millimeter (five mice per group). Microglia depletion did not affect the number of Olig2-positive cells. ns, Nonsignificant by Student's t test.

some treatment, enabling unprecedented investigations into their respective roles upon nerve injury.

\section{No effect of microglia depletion on axotomy-induced RGC degeneration}

We first investigated whether microglia depletion might either delay or accelerate axotomy-induced RGC degeneration. To this end, optic nerves of adult mice on either control or 3-week PLX5622 diet were crushed intraorbitally and retinae isolated 7, 10 , or $21 \mathrm{~d}$ thereafter to quantify surviving $\beta$ III-tubulin-positive RGCs (Leibinger et al., 2013a; Leibinger et al., 2016). Compared with uninjured mice, RGC numbers decreased continuously over time, with only $\sim 15 \%$ of RCCs remaining $21 \mathrm{~d}$ after ONC (Fig. 

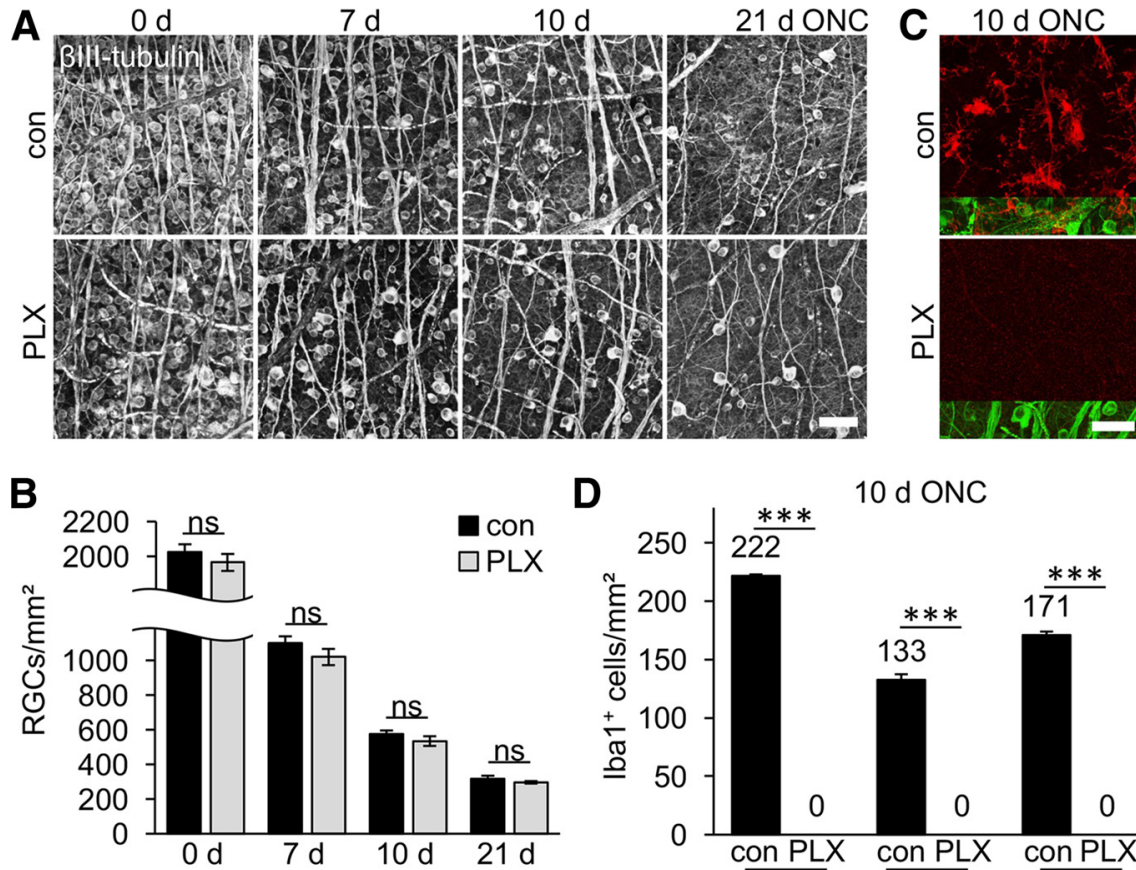

\section{D}

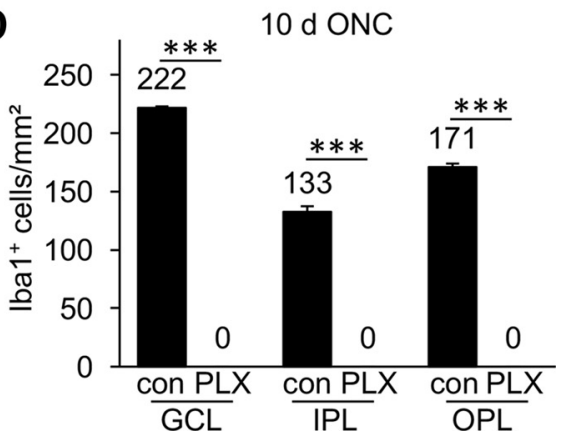

Figure 3. Axotomy-induced RGC degeneration is unaltered upon microglia depletion. $\boldsymbol{A}$, Representative photographs of $\beta$ IIItubulin-stained flat-mounted retinae isolated either from untreated control (con) or PLX5622-treated (PLX) mice at 0,7, 10, and $21 \mathrm{~d}$ after ONC. Scale bar, $50 \mu \mathrm{m}$. B, Quantification of surviving RGCs per square millimeter in flat-mounted retinae as indicated in A. Numbers of surviving $\beta$ III-tubulin-positive RGCs decreased gradually over time. Microglia depletion had no impact on RGC survival at any time point analyzed. ns, Nonsignificant by one-way ANOVA with Holm-Sidak post hoc test. Data represent mean values \pm SEM of at least 4 mice per experimental group (con $0 \mathrm{~d}: n=11,7 \mathrm{~d}: n=4,10 \mathrm{~d}: n=6,21 \mathrm{~d}: n=6 ;$ PLX $0 \mathrm{~d}: n=6,7 \mathrm{~d}$ : $n=4,10 \mathrm{~d}: n=6,21 \mathrm{~d}: n=7)$. C, Representative confocal photographs of flat-mounted retinae showing Iba1-positive reactive microglia with short and thick protrusions (red) in the $\mathrm{GCL}$ of control retinae $10 \mathrm{~d}$ after ONC. Coimmunostaining for $\beta$ III-tubulin (green) was used to detect RGCs' somata and axons. No lba1-positive cells were detected in PLX-treated animals. Scale bar, $25 \mu \mathrm{m}$. D, Quantification of Iba1-positive cells in respective cell layers (GCL, IPL, and OPL) of flat-mounted retinae in control- and PLXtreated mice $10 \mathrm{~d}$ after $0 \mathrm{NC}$ as presented in C. Mean microglia numbers per square millimeter are depicted above the respective columns and are increased throughout all layers upon ONC compared with noninjured mice (Fig. 1C). No microglia were detected upon PLX treatment. Treatment effects: ${ }^{* * *} p<0.001$. ns, Nonsignificant by one-way ANOVA with Holm-Sidak post hoc test. Cells were quantified in four (con) and six (PLX) different retinae, respectively.

$3 A, B)$. Interestingly, the numbers of RGCs in PLX5622-treated retinae were very similar to untreated controls at each time point analyzed, indicating that microglia depletion had no impact on the survival of axotomized RGCs. In light of these results, we considered the possibility that PLX5622 might be inefficient in depleting activated microglia upon ONC. We therefore quantified Iba1-positive cells in retinae of control and PLX5622-treated mice $10 \mathrm{~d}$ after ONC (Fig. 3C,D). Compared with naive animals (Fig. 1C), ONC increased microglia numbers, particularly in the GCL (3.6-fold), but also in IPL and OPL (1.7- and 1.9-fold, respectively), of otherwise untreated retinae. In addition, microglia morphology changed toward shorter and thicker protrusions after ONC, indicative of activation (Fig. 3C) (Davalos et al., 2005; Rice et al., 2015). However, not a single Iba1-positive cell was detected in retinae of mice on PLX5622 diet (Fig. 3C,D), confirming efficient depletion of retinal microglia upon ONC. To exclude the possibility that the Ibal epitope rather than the microglia themselves disappeared upon PLX5622 treatment, we also detected reactive microglia using an antibody against CD11b (Fig. 4A). Consistently, double Iba1- and CD11b-positive microglial cells were detected on sections of control, but not PLX5622-treated, retinae isolated $10 \mathrm{~d}$ after ONC. In addition, microglia were tagged indirectly upon phagocytosis of before retrogradely labeled RGCs (Mey and Thanos, 1993; Fischer et al., 2000; Thanos et al., 2000; Fischer et al., 2001).
Accordingly, 4-Di-10-ASP-positive microglia were detected alongside labeled RGCs in control retinae 2 weeks after positioning dye crystals at the proximal stumps of transected optic nerves (Fig. 4B). In contrast, 4-Di-10ASP-fluorescent RGCs, but no Ibal-positive cells, were detected in PLX5622-treated retinae, providing further evidence for successful depletion of retinal microglia. The presence of 4-Di-10-ASP-positive cell remnants (Fig. $4 B$ ) and the absence of other labeled cells indicated that neither infiltrating macrophages nor other retinal cells supported the clearance of dead RGCs in the absence of microglia.

\section{No impact of microglia and infiltrated macrophages on LI-stimulated RGC survival}

LI transforms RGCs into a regenerative state, delaying RGC degeneration and enabling moderate axon regeneration into the lesioned optic nerve (Fischer et al., 2000; Yin et al., 2003). The beneficial effects of LI are mainly mediated by activated retinal astrocytes and Müller glia, which secrete growth-promoting molecules such as ciliary neurotrophic factor and leukemia inhibitory factor (Müller et al., 2007; Leibinger et al., 2009; Leibinger et al., 2013b). In addition, this treatment activates resident retinal microglia and recruits macrophages into the retina and vitreous body (Yin et al., 2003; Hauk et al., 2008). The role of recruited macrophages in this context has been a matter of debate (Cui et al., 2009; Fischer, 2008; Hauk et al., 2008) and the contribution of microglia has so far remained elusive. We therefore decided to next investigate the role of microglia as well as infiltrated macrophages under these neuroprotective and proregenerative conditions in mice. Ibal immunostaining revealed the presence of many positive cells with short and thick protrusions in the GCL, IPL, and OPL of otherwise untreated control retinae $21 \mathrm{~d}$ after combined ONC and LI (Fig. $5 A, B)$. In contrast to mice only receiving ONC (Fig. $3 C, D$ ), some Iba1-positive cells were detected in retinae of mice on the PLX5622 diet after ONC+LI, likely representing infiltrated macrophages. To test this hypothesis, we cotreated some mice with PLX5622 and clodronate liposomes. Intraperitoneally injected clodronate liposomes eliminated the majority of peripheral macrophages (Fig. 2A), but had no effect on microglia (Hauk et al., 2008; Horn et al., 2008). The cotreatment almost completely eliminated Iba1-positive cells in all retinal layers (Fig. 5A,B). Therefore, LI caused indeed some influx of peripheral monocytes, but the vast majority of Iba1-positive cells in the retina represent activated microglia. To confirm the absence of microglia/macrophages under these experimental conditions, we additionally performed quantitative RTPCR analysis for Csf1r. Consistent with microglia activation and proliferation, Csflr mRNA levels were considerably elevated upon ONC ( $\sim 7$-fold) compared with untreated control mice (Fig. $5 C$ ). Expression further increased upon additional LI $(\sim 10$-fold compared with uninjured animals), at least partly reflecting the infiltration of peripheral monocytes/macrophages. PLX5622 treatment was 
sufficient to eliminate virtually all Csflr expression in naive retinae and upon ONC (Fig. 5C). However, some Csflr mRNA was still detected upon ONC+LI, consistent with the presence of PLX-unresponsive macrophages. Similar to Iba1 immunostaining (Fig. 5A), Csf1r expression disappeared upon cotreatment with clodronate liposomes (Fig. 5C). Therefore, PLX efficiently eliminated microglia from the retina upon ONC+LI, but the invasion of peripheral monocytes/macrophages required cotreatment with clodronate to remove all Iba1/Csflr-positive cells.

Regarding axotomy-induced RGC degeneration, LI significantly increased the number of surviving RGCs compared with $21 \mathrm{~d}$ after just ONC (Fig. 5D,E) (Leibinger et al., 2009), but RGC numbers in PLX5622-, clodronate-, and PLX5622 + clodronate-treated retinae were very similar to the respective controls (Fig. 5D,E). Therefore, the absence of microglia, macrophages, or both cell types did not influence LI-mediated neuroprotection measurably.

\section{Microglia depletion does not affect the regenerative state of injured RGCs} Because microglia depletion had no impact on RGC survival after ONC or ONC+LI, we wondered whether retinal microglia might at all influence the regenerative potential of RGCs. We therefore tested the expression of the selected proregenerative genes Gap43, Galanin, and Sprrla because their induction is reportedly associated with successful transformation of RGCs into a regenerative state and axon regeneration ( $\mathrm{Fi}-$ scher et al., 2004; Leibinger et al., 2009; Heskamp et al., 2013; Leibinger et al., 2013a). Accordingly, expression of all three genes, as detected by quantitative RT-PCR, was increased $5 \mathrm{~d}$ after $\mathrm{ONC}$ and even further after ONC+LI compared with uninjured controls (Fig. 6A-C). PLX5622 and even PLX5622+clodronate treatment, however, had no influence on these expression profiles. Therefore, depletion of microglia or macrophages had seemingly no obvious direct and/or indirect effect on LI-mediated growth promotion. To corroborate these findings, we additionally analyzed spontaneous neurite outgrowth (within $24 \mathrm{~h}$ ) of in vivo primed adult RGCs in culture, which reflects the intrinsic regenerative capacity of these neurons (Fischer et al., 2004; Müller et al., 2007; Leibinger et al., 2009). Consistent with the quantitative RT-PCR data, no difference in mean neurite length was observed between RGCs isolated from control, PLX5622-, clodronate-, and PLX5622 + clodronate-treated mice (Fig. 6D-F). Therefore, neither microglia activation, macrophage infiltration nor absence of both cell types seemingly influenced the regenerative state of injured RGCs.

\section{Microglia depletion affects astrocyte recruitment, but not axonal regeneration in vivo}

So far, our results indicated that retinal microglia are indeed involved in the clearance of RGC debris, but have no impact on the regenerative state or the survival of axotomized RGCs. How- ever, axon regeneration might still be (positively or negatively) influenced by microglia within the optic nerve. Immunohistochemistry at $21 \mathrm{~d}$ after ONC revealed the presence of many Iba1positive cells along the entire optic nerve, comparable to uncrushed specimens (Figs. $7 A, 1 D$ ). In addition, quite a few cells accumulated around the crush site, as described previously $(\mathrm{Qu}$ and Jakobs, 2013). Similar staining patterns were also observed $21 \mathrm{~d}$ after combined ONC+LI, suggesting that inflammatory stimulation is mostly confined to the eye and does not affect macrophage infiltration into the injured optic nerve (Fig. 7A). After PLX5622 treatment, Iba1-positive cells were no longer detected along the nerve, but were still found around the lesion site both after ONC and ONC+LI, indicating that many of these cells were infiltrated macrophages rather than microglia (Fig. $7 A$ ). Accordingly, cotreatment with PLX5622 and clodronate liposomes eradicated almost all Ibal staining (Fig. $7 B$ ). In this way, microglia became distinguishable from infiltrated macrophages and their respective contributions to optic nerve regeneration could be analyzed.

First, we characterized the effect of microglia/macrophage depletion on the environment of the lesion site. For example, it is well known that astrocytes, similar to microglia, become activated upon nerve injury to repopulate the lesion site, thereby 

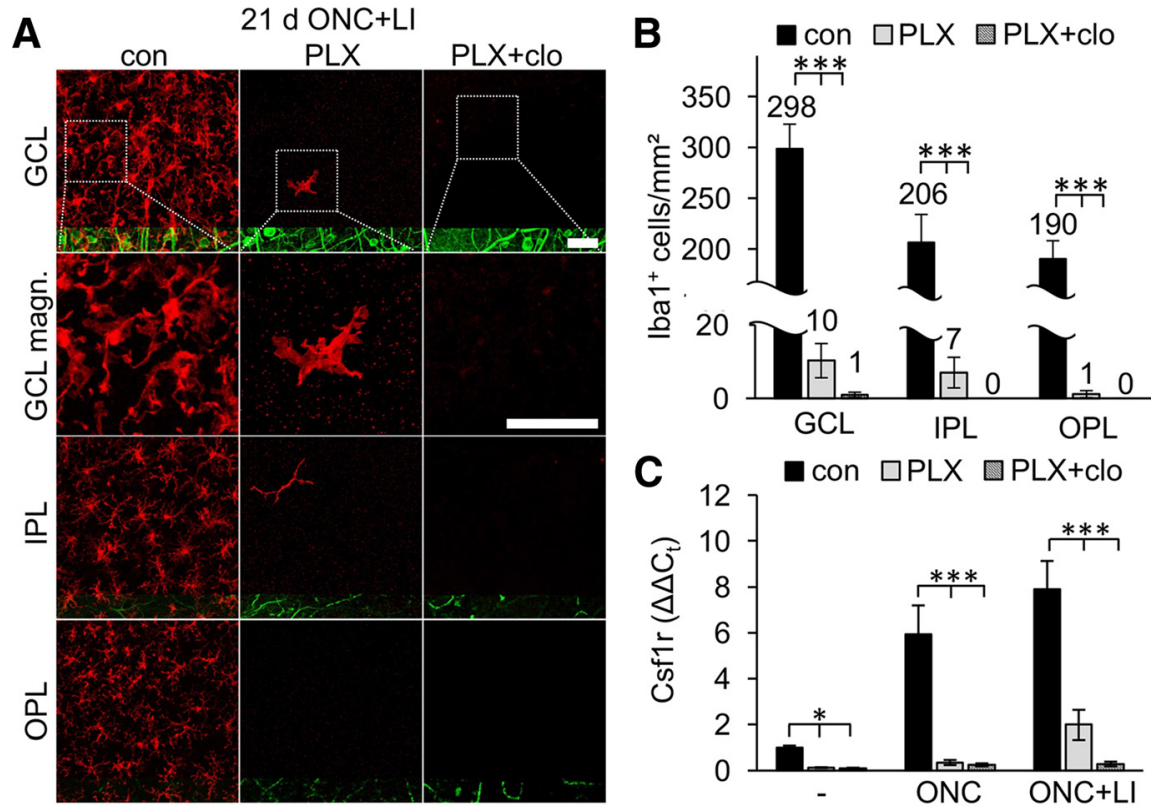

D
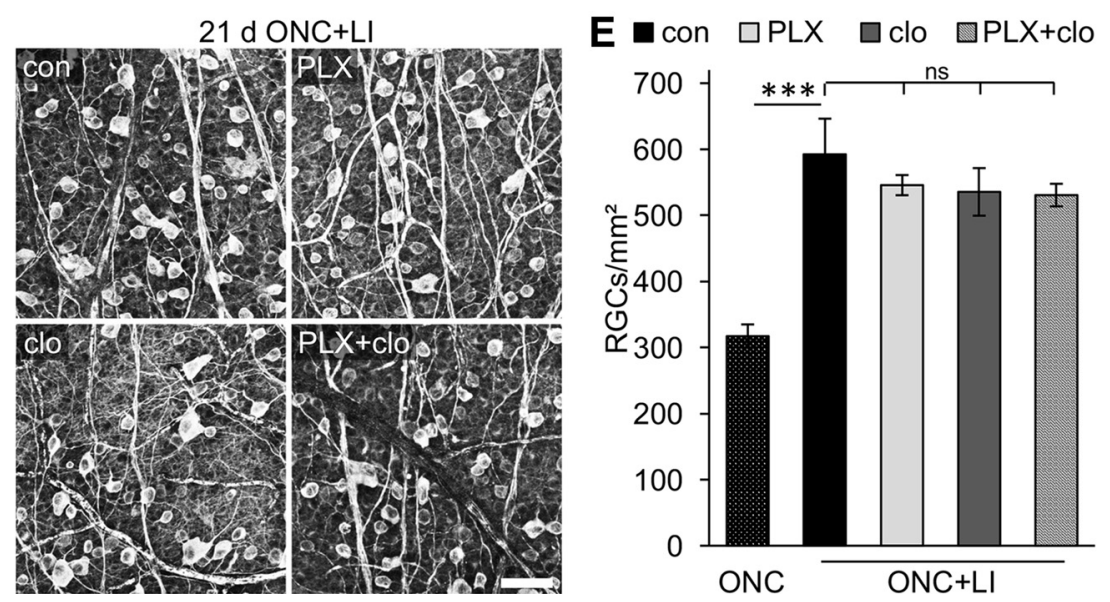

Figure 5. Microglia and infiltrating macrophages have no impact on the survival of regeneration-competent axotomized RGCS $A$, Confocal images of flat-mounted murine retinae show the distribution and morphology of lba1-positive cells (red) in respective retinal layers $21 \mathrm{~d}$ after $\mathrm{ONC}+\mathrm{Ll}$, which increases the regenerative potential of RGCs. In otherwise untreated retinae (con), Iba1-positive cells were identified in the GCL, IPL, and OPL. In contrast to sole ONC (Fig. 3), a few Iba1-positive cells were detected in the GCL and IPL of PLX5622 (PLX)-treated mice $21 \mathrm{~d}$ after ONC + LI. These cells likely represent infiltrated macrophages because they disappeared upon combined treatment with PLX and clodronate liposomes (PLX+Clo). For spatial orientation, coimmunostaining for $\beta$ III-tubulin (green) was used to detect RGCS and their axons in the GCL, whereas blood vessels were nonspecifically labeled in the IPL and OPL. Dashed boxes indicate areas in the GCL magnified in the second row (GCL magn.). Scale bars, $50 \mu \mathrm{m}$. B, Quantification of lba1-positive cells in respective layers ( $G C L, I P L$, and OPL) of flat-mounted retinae in experimental groups as described in $\boldsymbol{A}$. Cell numbers are depicted above the respective columns. Almost no lba1-positive cells were detected upon combined treatment with PLX+clo. Treatment effects compared with controls: ${ }^{* * *} p<0.001$ by one-way ANOVA with Holm-Sidak post hoc test. Cells were quantified in six (con), six (PLX), and four (PLX+clo) different retinae, respectively. $\boldsymbol{C}$, Quantitative RT-PCR analysis of (sf1r, a marker for microglia and macrophages, in retinae of either PLX-treated or combined PLX + clodronate liposomes (PLX+clo)-treated mice compared with untreated controls (con). Retinae were isolated from naive mice $(-)$ or animals that received either $\mathrm{ONC}$ or $\mathrm{ONC}+\mathrm{LI}$ for $5 \mathrm{~d}$ before tissue isolation. Csf1r mRNA levels were strongly elevated upon ONC and even further upon ONC $+\mathrm{LI}$ in con mice. PLX treatment eliminated Csf1r expression in retinae from con and ONC-treated mice and clodronate liposomes had no further effect under these conditions. In contrast, low Csf1r expression was still detected in PLX-treated animals after ONC+LI, which was diminished by additional injections of clodronate liposomes. Treatment effects compared with controls: ${ }^{*} p<0.05 ;{ }^{* * *} p<0.001$ by two-way ANOVA with Holm-Sidak post hoc test for 3 animals per experimental group. $\boldsymbol{D}$, Representative photographs of $\beta$ III-tubulin-stained flat-mounted retinae isolated either from otherwise untreated con, PLX-treated, clodronate liposome (clo)-treated, or PLX + clo-treated mice at $21 \mathrm{~d}$ after ONC + LI. Scale bar, $50 \mu \mathrm{m} . \boldsymbol{E}$, Quantification of surviving RGCs in flat-mounted retinae as indicated in D. RGC numbers after sole ONC (stippled bar, data from Fig. $2 B$ ) were included to illustrate the neuroprotective effect of LI. RGC survival and LI-mediated neuroprotection were completely unaffected by microglia (PLX), macrophage ( $\mathrm{Cl} 0)$, and microglia + macrophage (PLX+clo) depletion. Treatment effects compared with controls: ${ }^{* * *} p<0.001$. ns, Nonsignificant by one-way ANOVA with Holm-Sidak post hoc test. Cells were quantified in six con, six $P L X$, four clo, and four PLX+clo-treated retinae, respectively. contributing to the formation of a glial scar (Silver and Miller, 2004). Costaining of Ibal and GFAP revealed that repopulation of the lesion site by astrocytes was delayed upon PLX5622 treatment because a larger, seemingly cell-free area with strongly reduced GFAP staining was observed in these optic nerves at $10 \mathrm{~d}$ after ONC (Fig. $7 B, D, E$ ). The size of the area with reduced GFAP staining and the staining intensity around the lesion site were similar in PLX5622-treated and PLX5622 + clodronate-treated mice (Fig. $7 D, E)$, indicating that microglia, rather than macrophages, are required for this astrocyte recruitment. However, significant differences in area size and staining intensity between these three experimental groups were no longer detected $21 \mathrm{~d}$ after injury, although area sizes tended to be slightly larger in PLX5622 + clodronate-treated mice (Fig. 7C-E). Therefore, microglia seem to have a rather transient role in this process and their absence just delayed astrocyte repopulation of the lesion site.

Reactive astrocytes reportedly produce regeneration-inhibiting molecules but, conversely, they might bridge a lesion site to support axonal regeneration (Silver and Miller, 2004; Anderson et al., 2016). Therefore, we next analyzed the impact of microglia depletion (and thus delayed repopulation by astrocytes) on axon regeneration in vivo. Optic nerves of mice on either control or sustained PLX5622 diet were intraorbitally crushed and regenerating axons quantified $21 \mathrm{~d}$ thereafter using anterograde CTB labeling. Microglia depletion had no discernable effect on axon regeneration (Fig. $8 A, B$ ). Therefore, we next investigated whether microglia might affect LI-induced optic nerve regeneration. LI enables axon growth beyond the injury site, but there was again no difference in the number of regenerating axons or the average length of the longest fibers in PLX5622-treated compared with control mice (Fig. 8C-E). Therefore, microglia within the optic nerve neither supported nor inhibited axon regeneration and growing axons were seemingly unimpaired by a temporarily larger astrocyte gap at the lesion site. Similarly, sole macrophage depletion upon injection of clodronate liposomes had no effect on LIinduced axon regeneration (Fig. $8 C-E$ ), confirming previous findings that macrophage infiltration is irrelevant for the LImediated increase of the regenerative capacity of RGCs in rats (Müller et al., 2007; Hauk et al., 2008). In contrast, numbers of regenerating axons, but not 
the average length of the longest axons, were slightly but significantly decreased upon cotreatment with PLX5622 and clodronate liposomes (Fig. 8C-E). Therefore, a microglia- and macrophage-free lesion site at least partially limited optic nerve regeneration.

\section{Discussion}

The role of microglia in CNS degenerative and regenerative processes is still ambiguous because both beneficial and detrimental effects have been proposed. Taking advantage of PLX5622-triggered microglia depletion, this study investigated the role of these cells in RGC degeneration and axonal regeneration upon ONC. We demonstrate here that PLX5622 efficiently and specifically depleted microglia in the mouse visual system without any discernable effect on other cell populations. Upon axotomy, microglia depletion impaired the removal of degenerated RGCs and delayed the repopulation of the optic nerve lesion site by astrocytes. Despite these noticeable changes, neither lesion-induced RGC degeneration nor spontaneous and LI-induced optic nerve regeneration were affected in the absence of microglia. Therefore, our data indicate that, contrary to previous reports, microglia are not substantially involved in degenerative or regenerative processes after acute optic nerve injury.

Previous studies showed that oral administration of either the dual CSF1R/cKit inhibitor PLX3397 or the more specific CSF1R inhibitor PLX5622 efficiently reduced microglia numbers by 90-99\% in adult mouse brains (Elmore et al., 2014; Dagher et al., 2015; Spangenberg et al., 2016; Szalay et al., 2016). Consistently, we found that PLX5622 was at least as, if not more, efficient in the visual system because no Ibal-positive cells were detected in retinae and at best, only very few remained in optic nerves after continuous drug treatment for 3 weeks. These cells represent either PLX-resistant, nondepleted microglia (Rice et al., 2015; Spangenberg et al., 2016) or infiltrated macrophages. PLX5622induced retinal microglia deficiency was also more pronounced compared with a genetic approach, which showed only nearcomplete depletion and some long-term repopulation (Wang et al., 2016). Treatment times might possibly be reducible, but we found that 1 week of PLX5622 diet was insufficient to achieve complete depletion, similar to previous studies in brain (Elmore et al., 2014). Moreover, other cells of the nervous system, such as RGCs, astrocytes, oligodendrocyte lineage cells, and peripheral macrophages in the spleen, also remained unaffected upon PLX5622 treatment (Szalay et al., 2016; Wang et al., 2016).

ONC reportedly increases microglia numbers in the retina (Mey and Thanos, 1993; Garcia-Valenzuela et al., 2005; Wohl et al., 2010). The current study demonstrates consistently that this rise was particularly pronounced in the GCL. Nevertheless, Iba1positive cells were also not detectable in retinae of injured mice after PLX5622 treatment. The absence of microglia, rather than
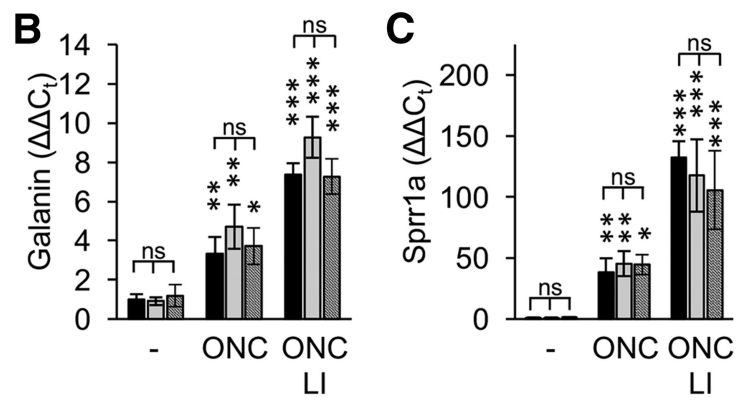

LI
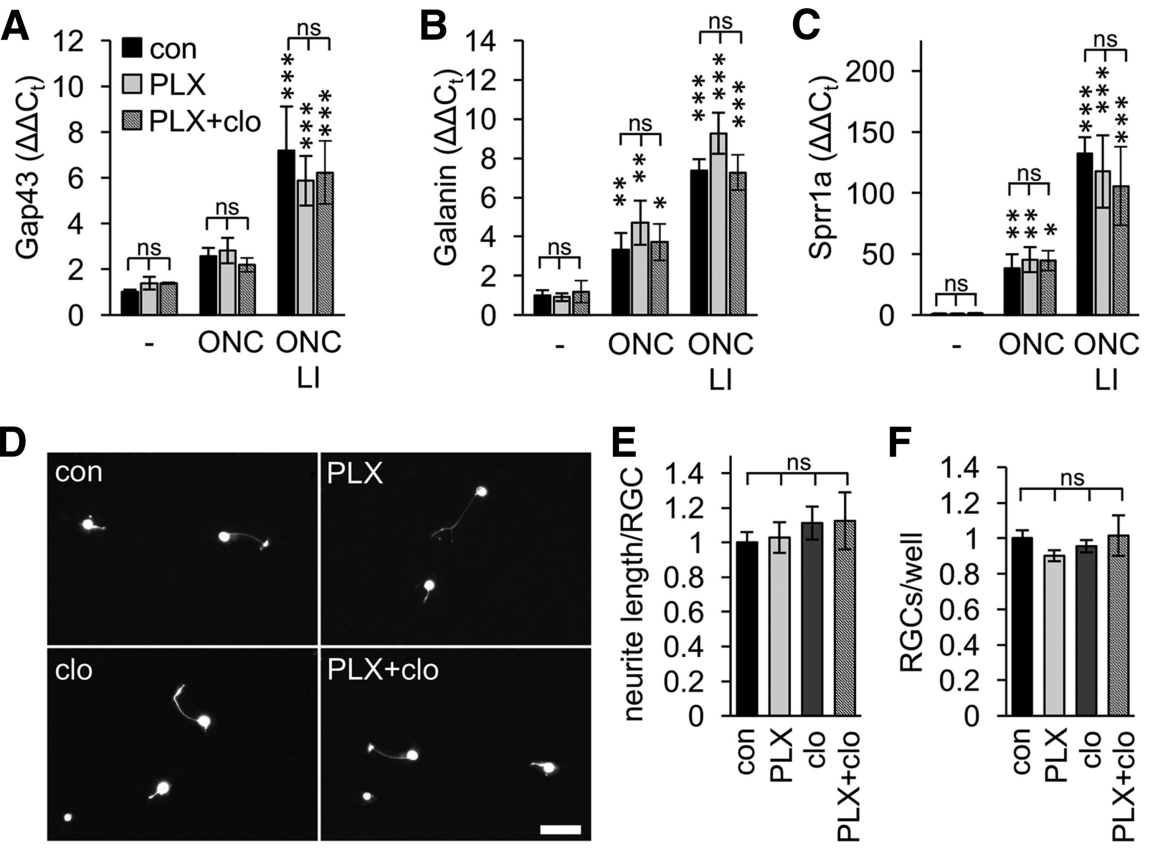

Figure 6. $\mathrm{RGCs}$ intrinsic regenerative capacity is unaltered in microglia-depleted mice. $\boldsymbol{A}-\boldsymbol{C}$, Quantitative RT-PCR analysis of animals that had received either $0 \mathrm{NC}$ or $\mathrm{ONC}+\mathrm{LI} 5 \mathrm{~d}$ before tissue isolation. ONC, particularly $\mathrm{ONC}+\mathrm{LI}$, induced the expression of experimental group. D, Representative photographs of dissociated adult RGCs isolated from mice on either control (con) or PLX diet ( 作 isolation neurite length of $3.0 \mu \mathrm{m} / \mathrm{RGC}$ and represent means \pm SEM of at least three independent experiments. In total, 22 con, $24 \mathrm{PLX}-, 12$ $\boldsymbol{F}$, Quantification of RGC numbers in retinal cultures as in D.PLX, clo, or combined PLX + clo treatment before tissue isolation had no impact on RGC survival in culture. Data were normalized to controls at $1 \mathrm{~d}$ with an average number of $580 \mathrm{RGCS} /$ well and represent means \pm SEM from the same experimental groups as in $\boldsymbol{E}$. ns, Nonsignificant by one-way ANOVA with Holm-Sidak post hoc test.

masking of the Ibal epitope, was further verified using Csflr RT-PCR, CD11b immunostaining, and retrograde labeling, confirming previously published data using lineage tracing (Spangenberg et al., 2016). Therefore, PLX5622 is similarly effective in the naive and injured visual system. In addition, these experiments revealed that peripheral macrophages only infiltrated the optic nerve lesion site, not the various retinal layers after ONC. In contrast, LI is known to recruit peripheral macrophages into the retina and vitreous body (Yin et al., 2003; Hauk et al., 2008). Accordingly, a few Iba1-positive cells were detected in PLX5622treated retina upon combination of ONC and LI. However, these cells were effectively diminished via additional treatment with clodronate liposomes, which depletes peripheral monocytes/macrophages before infiltration of the retina, but not resident microglia. In this way, potential nondepleted retinal microglia became distinguishable from infiltrated macrophages. Similarly, Ibal staining around the optic nerve lesion site was only resolved upon combination of PLX5622 diet and clodronate liposome injection, indicating localized infiltration of peripheral macrophages in addition to microglia activation, as was observed previously after spinal cord injury (Evans et al., 2014). For sustained microglia depletion, mice were precautionally kept on the PLX5622 diet throughout the experiments because it is currently unknown whether microglia would be able to repopulate retinal tissues upon cessation of treatment as de- 

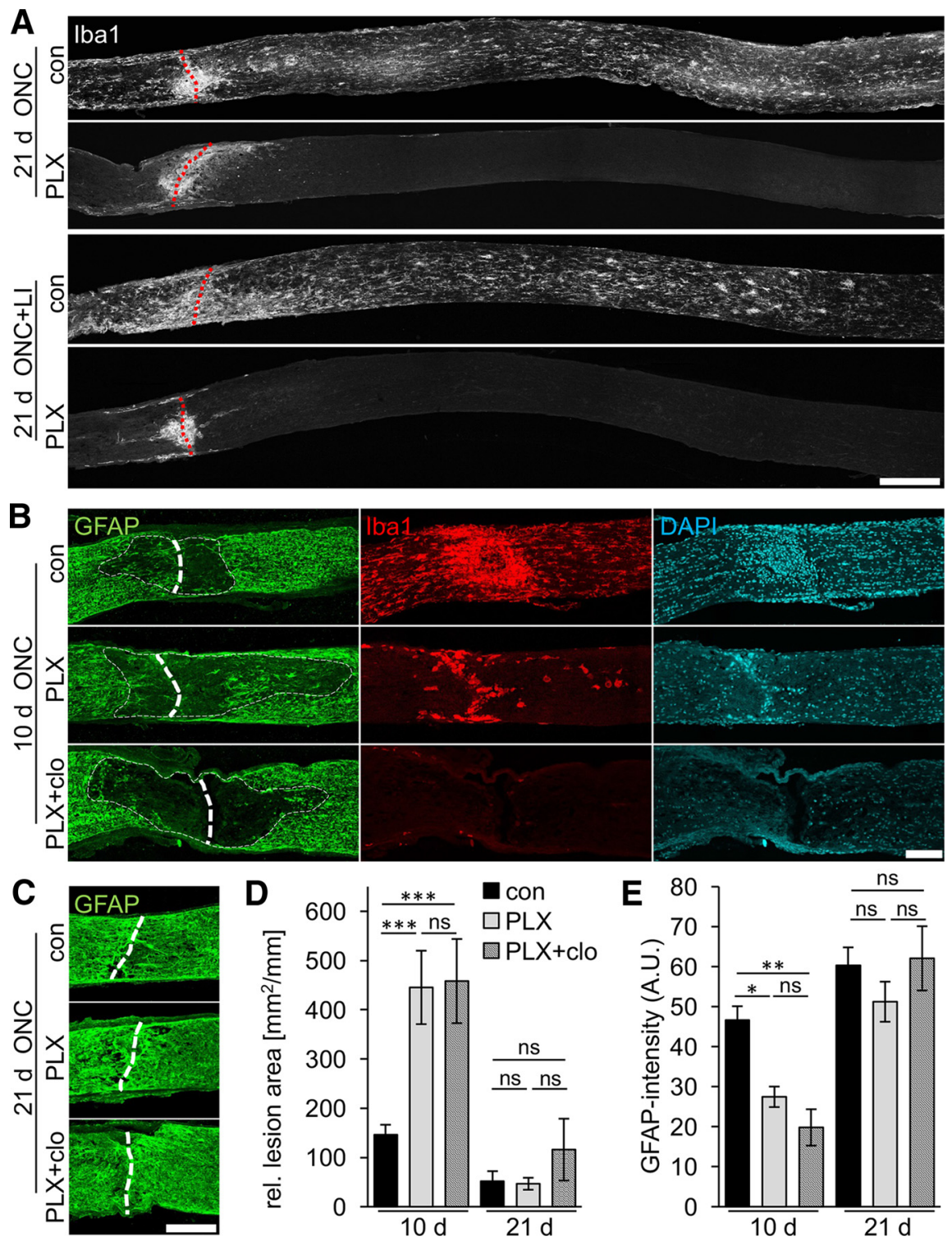

Figure 7. Delayed repopulation of the optic nerve lesion site by astrocytes upon microglia depletion. $\boldsymbol{A}$, lba1 staining of longitudinally sectioned optic nerves isolated $21 \mathrm{~d}$ after ONC or ONC + LI. Iba1-positive cells were detected along the whole optic nerve of mice on control diet (con), with some cell accumulation at the injury site (dashed red line). In contrast, Iba1-positive cells were only found around the lesion site in PLX-treated animals both after ONC or ONC+LI, likely representing infiltrated macrophages. Scale bar, $200 \mu \mathrm{m}$. B, Representative photographs of the optic nerve lesion site of mice on either control diet (con), PLX5622 diet (PLX) or PLX diet + clodronate treatment (PLX+clo) that were costained for GFAP (green), Iba1 (red), and DAPI (blue) $10 \mathrm{~d}$ after ONC. The area of reduced GFAP staining around the lesion site (dashed line) was larger upon both PLX and PLX $+\mathrm{clo}$ treatment than controls. PLX treatment reduced the number of lba1-positive cells around the lesion sites, whereas none were detected upon PLX + clo treatment. DAPI staining confirmed the presence of fewer cells around the lesion site upon PLX and $\mathrm{PLX}+$ clo treatments. Scale bar, $100 \mu \mathrm{m}$. C, Representative photographs of GFAP-stained optic nerve lesion sites of mice as in B 21 d after ONC. Astrocytes repopulated the lesion site in all three experimental groups. Scale bar, $100 \mu \mathrm{m}$. D, Quantification of the lesion area size identified by reduced GFAP staining relative to the optic nerve width on sections as in $\boldsymbol{B}$ and $\boldsymbol{C}$. The lesion site was significantly larger upon PLX and PLX + clo treatments compared with controls at $10 \mathrm{~d}$, but similar at $21 \mathrm{~d}$ after ONC. Treatment effects: ${ }^{* * *} p<0.001$. ns, Nonsignificant by two-way ANOVA with Holm-Sidak post hoc test. The area size was quantified on 4 sections per optic nerve for $5-9$ mice per experimental group (con $10 \mathrm{~d}: n=24,21 \mathrm{~d}: n=32 ; \mathrm{PLX}: 10 \mathrm{~d}: n=24,21 \mathrm{~d}: n=36 ; \mathrm{PLX}+\mathrm{clo}: 10 \mathrm{~d}: n=20,21 \mathrm{~d}: n=20$ sections). $\boldsymbol{E}$, Quantification of GFAP fluorescence intensity within the lesion site on sections as in $\boldsymbol{B}$ and $\boldsymbol{C}$. Mean gray values within a $500 \times 150 \mu \mathrm{m}$ sector centered at the lesion site were determined in arbitrary units (A.U.). GFAP staining intensity was significantly reduced upon PLX and $\mathrm{PLX}+$ clo treatments compared with controls at $10 \mathrm{~d}$, but similar at $21 \mathrm{~d}$ after $0 \mathrm{NC}$. Treatment effects: ${ }^{*} p<0.05,{ }^{* *} p<0.01$. ns, Nonsignificant by two-way ANOVA with Holm-Sidak post hoc test for the same specimens as in $\boldsymbol{D}$.

scribed for brain tissues (Dagher et al., 2015; Elmore et al., 2015). Overall, pharmacological CSF1R inhibition was deemed a suitable approach to investigate the specific role of microglia in axotomyinduced RGC degeneration and optic nerve regeneration.
Remarkably, PLX5622-triggered microglia depletion had no effect on axotomy-induced RGC degeneration, neither improving nor impairing their survival. These results stand in contrast to previous pharmacologic approaches that suggested a rather detrimental impact because repression of microglia activation transiently delayed apoptosis of RGCs after optic nerve injury (Mey and Thanos, 1993; Baptiste et al., 2005; Levkovitch-Verbin et al., 2006; Bosco et al., 2008; Jiao et al., 2014). One explanation for these apparently conflicting outcomes could be the use of minocycline, which reportedly not only impairs microglia activation, but also affects peripheral macrophages and T cells (Hellwig et al., 2013). Moreover, this drug might even promote neuronal survival directly (Jiao et al., 2014). Similarly, the tripeptide Thr-Lys-Pro was originally described as an inhibitor of IgEdependent macrophage stimulation (Auriault et al., 1983) and indirect effects of intravitreal peptide application on RGC survival cannot be excluded (Mey and Thanos, 1993; Müller et al., 2009). Although our findings indicate that microglia are not involved in the initiation of axotomy-induced RGC death, they might nevertheless have an impact on the survival of other neuronal cell types or in other disease paradigms such as glaucoma or ischemia. Consistent with this idea, some studies reported prosurvival effects of microglia in brain injury models (Chen et al., 2012; Rice et al., 2015; Szalay et al., 2016). Whether microglia might also play a more prominent role in chronic RGC degeneration injuries such as glaucoma or multiple sclerosis will be addressed in future studies.

In our acute injury model, microglia seem to be activated subsequently to RGC death. Accordingly, it was not the induction of RGC degeneration, but rather the removal of 4-Di-10-ASPlabeled RGC remnants that was impaired upon PLX5622 treatment, indicating the requirement of microglia for this process. Seemingly, no other retinal cells could take over phagocytosis of apoptotic RGCs after ONC in adult mice, although minor involvement of dendritic cells has been proposed previously (Heuss et al., 2014). Nevertheless, the presence of labeled neuronal remnants in the retina evidently had no influence on the survival of the remaining RGCs, at least in the first 3 weeks after injury because axotomy-induced RGC degeneration/survival was overall unaffected upon microglia depletion. 
The intrinsic capacity of adult CNS neurons to regrow severed axons is generally low, contributing to the lack of axonal regeneration after injury. However, RGCs can be transformed into an enhanced regenerative state by LI, which enables moderate axon regeneration into the lesioned optic nerve (Fischer et al., 2000; Yin et al., 2003; Fischer and Leibinger, 2012). We showed here for the first time that retinal microglia are dispensable for the beneficial processes triggered by LI. Neither expression of various regeneration associated genes nor spontaneous neurite growth in culture, both hallmarks of enhanced regenerative capacity (Fischer et al., 2004; Leibinger et al., 2009; Leibinger et al., 2012), was changed upon microglia or even microglia and macrophage depletion. Beyond the intrinsic regenerative potential of injured RGCs, axonal regeneration is reportedly influenced by extrinsic conditions of the optic nerve. Growth-inhibitory molecules within degrading myelin as well as the forming glial scar might impair axon extension beyond the lesion site (Fischer and Leibinger, 2012; Lu et al., 2014). Axonal growth cones have also been observed to retract upon direct contact with microglia and/or infiltrated macrophages in the injured spinal cord (Horn et al., 2008; Kitayama et al., 2011; Evans et al., 2014). Using differential and combinatorial treatments with PLX5622 and clodronate liposomes, Iba1positive cells within the optic nerve lesion site were mainly identified as microglia at $10 \mathrm{~d}$ and as infiltrated macrophages at $21 \mathrm{~d}$ after ONC, indicating slow and microglia-independent invasion of peripheral monocytes upon injury. Interestingly, the repopulation of the optic nerve lesion site by reactive astrocytes was markedly delayed upon microglia depletion. Secretory molecules released by activated microglia, which have been shown previously to contribute to the initiation of glial scar formation (Hanisch and Kettenmann, 2007; Cherry et al., 2014), are likely involved in this process, but identification of the exact mechanism was beyond the scope of the current study and requires future investigations. Although astrocytes reportedly form glial bridges to aid axonal growth across spinal cord lesions (Anderson et al., 2016), prolonged absence of this supportive glial cell type at the optic nerve lesion site upon microglia depletion had no effect on regenerative outcomes in mice with both normal and enhanced regenerative capacity. Consistent with a rather slow invasion of peripheral macrophages into the lesioned optic nerve, systemic clodronate treatment had similarly no effect on LIinduced axonal regeneration. However, depletion of both

C specimens as in $\boldsymbol{D}$.
A

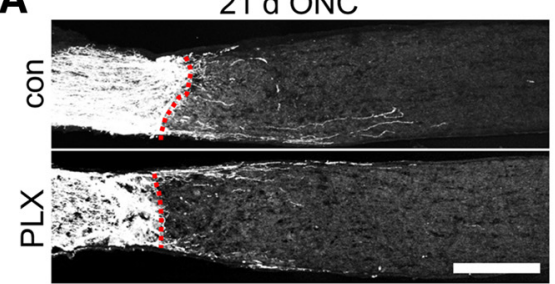

B
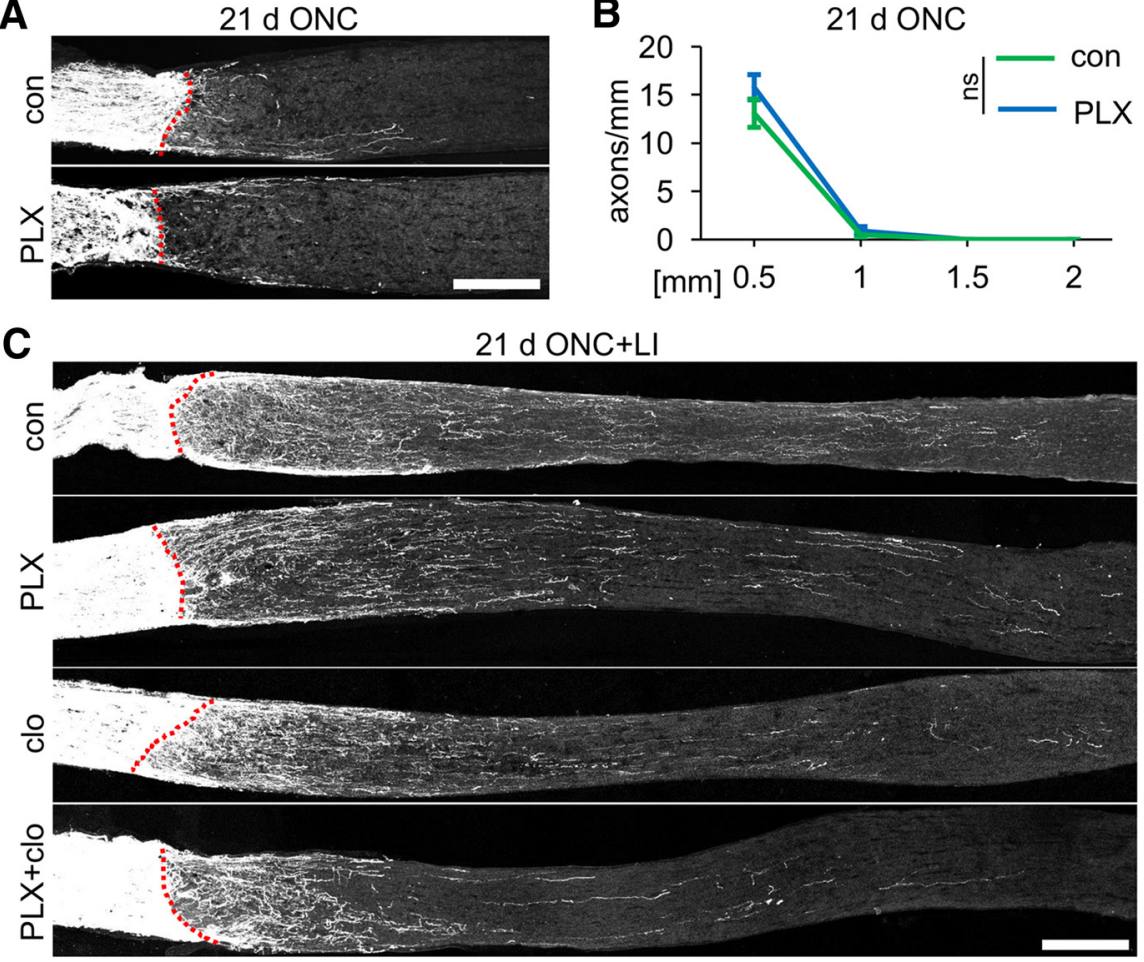

D

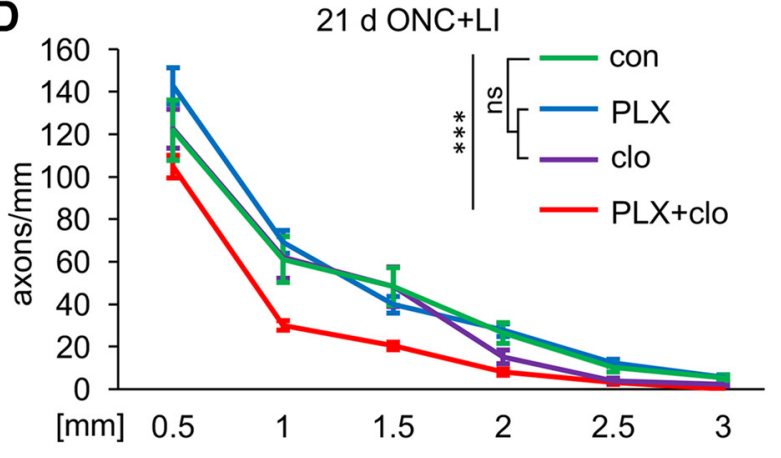

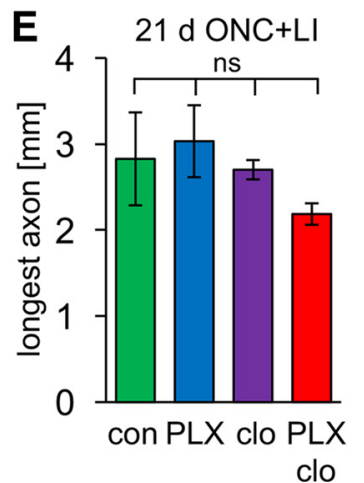

Figure 8. Optic nerve regeneration is only compromised upon codepletion of microglia and monocytes/macrophages. $A$, Representative photographs of optic nerve sections with (TB-labeled regenerating axons $21 \mathrm{~d}$ after ONC. Nerves were isolated from mice either on control (con) or PLX5622 diet (PLX). Dashed lines indicate the crush site. Scale bar, $250 \mu \mathrm{m}$. B, Quantification of regenerating axons extending $0.5,1,1.5$, and $2 \mathrm{~mm}$ from the injury site on sections as in $\boldsymbol{A}$. Spontaneous axon regeneration was unaffected by PLX treatment. ns, Nonsignificant by two-way ANOVA with Holm-Sidak post hoc test. Axons were quantified on five sections per nerve for five mice per experimental group $(n=25)$. C, Representative photographs of optic nerve sections with CTB-labeled regenerating axons $21 \mathrm{~d}$ after ONC+LI. Respective mice were either on control (con) or PLX diet (PLX) and some received intraperitoneal injections of clodronate liposomes (clo and $P L X+$ clo, respectively). Dashed lines indicate the lesion site. Scale bar, $250 \mu \mathrm{m}$. D, Quantification of regenerating axons extending $0.5,1,1.5,2,2.5$, and $3 \mathrm{~mm}$ from the injury site on sections as in C. Optic nerve regeneration was unaffected by the depletion of either microglia (PLX) or infiltrating macrophages (clo) compared with controls (con), but double depletion of both cell types ( $P L X+$ clo) slightly but significantly reduced the number of regenerating axons. Treatment effects: ${ }^{* * *} p<0.001$. ns, Nonsignificant by two-way ANOVA with Holm-Sidak post hoc test. Axons were quantified on five sections per nerve for five to eight mice per experimental group (con: $n=30$; PLX: $n=40$; clo: $n=$ 25; PLX + clo: $n=25)$. $E$, Quantification of the longest regenerating axon per section for experimental groups as described in C. Average length of the longest axons was unaffected by depletion of microglia (PLX), infiltrating macrophages (clo), or both cell types ( $P L X+$ clo) compared with controls. ns, Nonsignificant by one-way ANOVA with Holm-Sidak post hoc test for the same

resident microglia and infiltrated macrophages slightly but significantly compromised optic nerve regeneration, suggesting that one cell type might be able to take over functions of the other in their respective absence. For example, removal of (inhibitory) cellular debris from the lesion site or provision of structural support either by microglia or macrophages may allow more axons 
to initially grow beyond the lesion site (Neumann et al., 2009; Tanaka et al., 2009; Lampron et al., 2015). In support of this notion, the average length of the longest regenerated axons was not reduced by the absence of microglia and macrophages. Nevertheless, identification of the molecular mechanisms underlying this finding awaits further analyses.

Overall, our findings indicate the involvement of microglia in the clearance of apoptotic RGCs and the repopulation of the optic nerve lesion site by astrocytes. However, the progression of neuronal degeneration and axon regeneration after acute ONC were unaffected upon microglia depletion, indicating that microglia are either dispensable for these processes or that regeneration promoting activities exactly balanced inhibiting outcomes to net nil effects. For the future, PLX5622-triggered microglia depletion provides a favorable experimental approach with which to investigate the role of these cells in other nervous system injuries and diseases such as spinal cord injury, ischemia, glaucoma, or multiple sclerosis.

\section{References}

Anderson MA, Burda JE, Ren Y, Ao Y, O'Shea TM, Kawaguchi R, Coppola G, Khakh BS, Deming TJ, Sofroniew MV (2016) Astrocyte scar formation aids central nervous system axon regeneration. Nature 532:195-200. CrossRef Medline

Auriault C, Joseph M, Tartar A, Capron A (1983) Characterization and synthesis of a macrophage inhibitory peptide from the second constant domain of human immunoglobulin G. FEBS Lett 153:11-15. CrossRef Medline

Baptiste DC, Powell KJ, Jollimore CA, Hamilton C, LeVatte TL, Archibald ML, Chauhan BC, Robertson GS, Kelly ME (2005) Effects of minocycline and tetracycline on retinal ganglion cell survival after axotomy. Neuroscience 134:575-582. CrossRef Medline

Bennett ML, Bennett FC, Liddelow SA, Ajami B, Zamanian JL, Fernhoff NB, Mulinyawe SB, Bohlen CJ, Adil A, Tucker A, Weissman IL, Chang EF, Li G, Grant GA, Hayden Gephart MG, Barres BA (2016) New tools for studying microglia in the mouse and human CNS. Proc Natl Acad Sci U S A 113:E1738-E1746. CrossRef Medline

Bosco A, Inman DM, Steele MR, Wu G, Soto I, Marsh-Armstrong N, Hubbard WC, Calkins DJ, Horner PJ, Vetter ML (2008) Reduced retina microglial activation and improved optic nerve integrity with minocycline treatment in the DBA/2J mouse model of glaucoma. Invest Ophthalmol Vis Sci 49:1437-1446. CrossRef Medline

Bruttger J, Karram K, Wörtge S, Regen T, Marini F, Hoppmann N, Klein M, Blank T, Yona S, Wolf Y, Mack M, Pinteaux E, Müller W, Zipp F, Binder H, Bopp T, Prinz M, Jung S, Waisman A (2015) Genetic cell ablation reveals clusters of local self-renewing microglia in the mammalian central nervous system. Immunity 43:92-106. CrossRef Medline

Chen Z, Jalabi W, Shpargel KB, Farabaugh KT, Dutta R, Yin X, Kidd GJ, Bergmann CC, Stohlman SA, Trapp BD (2012) Lipopolysaccharideinduced microglial activation and neuroprotection against experimental brain injury is independent of hematogenous TLR4. J Neurosci 32: 11706-11715. CrossRef Medline

Cherry JD, Olschowka JA, O’Banion MK (2014) Neuroinflammation and M2 microglia: the good, the bad, and the inflamed. J Neuroinflammation 11:98. CrossRef Medline

Cui Q, Yin Y, Benowitz LI (2009) The role of macrophages in optic nerve regeneration. Neuroscience 158:1039-1048. CrossRef Medline

Czeh M, Gressens P, Kaindl AM (2011) The yin and yang of microglia. Dev Neurosci 33:199-209. CrossRef Medline

Dagher NN, Najafi AR, Kayala KM, Elmore MR, White TE, Medeiros R, West BL, Green KN (2015) Colony-stimulating factor 1 receptor inhibition prevents microglial plaque association and improves cognition in 3xTg-AD mice. J Neuroinflammation 12:139. CrossRef Medline

Davalos D, Grutzendler J, Yang G, Kim JV, Zuo Y, Jung S, Littman DR, Dustin ML, Gan WB (2005) ATP mediates rapid microglial response to local brain injury in vivo. Nat Neurosci 8:752-758. CrossRef Medline

Diekmann H, Fischer D (2013) Glaucoma and optic nerve repair. Cell Tissue Res 353:327-337. CrossRef Medline

Elmore MR, Najafi AR, Koike MA, Dagher NN, Spangenberg EE, Rice RA, Kitazawa M, Matusow B, Nguyen H, West BL, Green KN (2014)
Colony-stimulating factor 1 receptor signaling is necessary for microglia viability, unmasking a microglia progenitor cell in the adult brain. Neuron 82:380-397. CrossRef Medline

Elmore MR, Lee RJ, West BL, Green KN (2015) Characterizing newly repopulated microglia in the adult mouse: impacts on animal behavior, cell morphology, and neuroinflammation. PLoS One 10:e0122912. CrossRef Medline

Evans TA, Barkauskas DS, Myers JT, Hare EG, You JQ, Ransohoff RM, Huang AY, Silver J (2014) High-resolution intravital imaging reveals that blood-derived macrophages but not resident microglia facilitate secondary axonal dieback in traumatic spinal cord injury. Exp Neurol 254:109_ 120. CrossRef Medline

Fischer D (2008) CNTF, a key factor mediating the beneficial effects of inflammatory reactions in the eye. Brain 131:e97. CrossRef

Fischer D (2012) Stimulating axonal regeneration of mature retinal ganglion cells and overcoming inhibitory signaling. Cell Tissue Res 349:7985. CrossRef Medline

Fischer D, Leibinger M (2012) Promoting optic nerve regeneration. Prog Retin Eye Res 31:688-701. CrossRef Medline

Fischer D, Pavlidis M, Thanos S (2000) Cataractogenic lens injury prevents traumatic ganglion cell death and promotes axonal regeneration both in vivo and in culture. Invest Ophthalmol Vis Sci 41:3943-3954. Medline

Fischer D, Heiduschka P, Thanos S (2001) Lens-injury-stimulated axonal regeneration throughout the optic pathway of adult rats. Exp Neurol 172:257-272. CrossRef Medline

Fischer D, Petkova V, Thanos S, Benowitz LI (2004) Switching mature retinal ganglion cells to a robust growth state in vivo: gene expression and synergy with RhoA inactivation. J Neurosci 24:8726-8740. CrossRef Medline

Garcia-Valenzuela E, Sharma SC, Piña AL (2005) Multilayered retinal microglial response to optic nerve transection in rats. Mol Vis 11:225-231. Medline

Grozdanov V, Muller A, Sengottuvel V, Leibinger M, Fischer D (2010) A method for preparing primary retinal cell cultures for evaluating the neuroprotective and neuritogenic effect of factors on axotomized mature CNS neurons. Curr Protoc Neurosci Chapter 3:Unit3 22. CrossRef Medline

Hanisch UK, Kettenmann H (2007) Microglia: active sensor and versatile effector cells in the normal and pathologic brain. Nat Neurosci 10:13871394. CrossRef Medline

Hauk TG, Müller A, Lee J, Schwendener R, Fischer D (2008) Neuroprotective and axon growth promoting effects of intraocular inflammation do not depend on oncomodulin or the presence of large numbers of activated macrophages. Exp Neurol 209:469-482. CrossRef Medline

Hellwig S, Heinrich A, Biber K (2013) The brain's best friend: microglial neurotoxicity revisited. Front Cell Neurosci 7:71. CrossRef Medline

Heskamp A, Leibinger M, Andreadaki A, Gobrecht P, Diekmann H, Fischer D (2013) CXCL12/SDF-1 facilitates optic nerve regeneration. Neurobiol Dis 55:76-86. CrossRef Medline

Heuss ND, Pierson MJ, Montaniel KR, McPherson SW, Lehmann U, Hussong SA, Ferrington DA, Low WC, Gregerson DS (2014) Retinal dendritic cell recruitment, but not function, was inhibited in MyD88 and TRIF deficient mice. J Neuroinflammation 11:143. CrossRef Medline

Horn KP, Busch SA, Hawthorne AL, van Rooijen N, Silver J (2008) Another barrier to regeneration in the CNS: activated macrophages induce extensive retraction of dystrophic axons through direct physical interactions. J Neurosci 28:9330-9341. CrossRef Medline

Jiao X, Peng Y, Yang L (2014) Minocycline protects retinal ganglion cells after optic nerve crush injury in mice by delaying autophagy and upregulating nuclear factor-kappaB2. Chin Med J (Engl) 127:1749-1754. Medline

Jin X, Yamashita T (2016) Microglia in central nervous system repair after injury. J Biochem 159:491-496. CrossRef Medline

Kitayama M, Ueno M, Itakura T, Yamashita T (2011) Activated microglia inhibit axonal growth through RGMa. PLoS One 6:e25234. CrossRef Medline

Kreutzberg GW (1996) Microglia: a sensor for pathological events in the CNS. Trends Neurosci 19:312-318. CrossRef Medline

Lampron A, Larochelle A, Laflamme N, Préfontaine P, Plante MM, Sánchez MG, Yong VW, Stys PK, Tremblay MÈ, Rivest S (2015) Inefficient clearance of myelin debris by microglia impairs remyelinating processes. J Exp Med 212:481-495. CrossRef Medline 
Leibinger M, Müller A, Andreadaki A, Hauk TG, Kirsch M, Fischer D (2009) Neuroprotective and axon growth-promoting effects following inflammatory stimulation on mature retinal ganglion cells in mice depend on ciliary neurotrophic factor and leukemia inhibitory factor. J Neurosci 29:14334-14341. CrossRef Medline

Leibinger M, Andreadaki A, Fischer D (2012) Role of mTOR in neuroprotection and axon regeneration after inflammatory stimulation. Neurobiol Dis 46:314-324. CrossRef Medline

Leibinger M, Andreadaki A, Diekmann H, Fischer D (2013a) Neuronal STAT3 activation is essential for CNTF- and inflammatory stimulationinduced CNS axon regeneration. Cell Death Dis 4:e805. CrossRef Medline

Leibinger M, Müller A, Gobrecht P, Diekmann H, Andreadaki A, Fischer D (2013b) Interleukin-6 contributes to CNS axon regeneration upon inflammatory stimulation. Cell Death Dis 4:e609. CrossRef Medline

Leibinger M, Andreadaki A, Gobrecht P, Levin E, Diekmann H, Fischer D (2016) Boosting central nervous system axon regeneration by circumventing limitations of natural cytokine signaling. Mol Ther.

Levkovitch-Verbin H, Kalev-Landoy M, Habot-Wilner Z, Melamed S (2006) Minocycline delays death of retinal ganglion cells in experimental glaucoma and after optic nerve transection. Arch Ophthalmol 124:520-526. CrossRef Medline

Lu Y, Belin S, He Z (2014) Signaling regulations of neuronal regenerative ability. Curr Opin Neurobiol 27:135-142. CrossRef Medline

Mey J, Thanos S (1993) Intravitreal injections of neurotrophic factors support the survival of axotomized retinal ganglion cells in adult rats in vivo. Brain Res 602:304-317. CrossRef Medline

Müller A, Hauk TG, Fischer D (2007) Astrocyte-derived CNTF switches mature RGCs to a regenerative state following inflammatory stimulation. Brain 130:3308-3320. CrossRef Medline

Müller A, Hauk TG, Leibinger M, Marienfeld R, Fischer D (2009) Exogenous CNTF stimulates axon regeneration of retinal ganglion cells partially via endogenous CNTF. Mol Cell Neurosci 41:233-246. CrossRef Medline

Neumann H, Kotter MR, Franklin RJ (2009) Debris clearance by microglia: an essential link between degeneration and regeneration. Brain 132:288295. CrossRef Medline

Nimmerjahn A, Kirchhoff F, Helmchen F (2005) Resting microglial cells are highly dynamic surveillants of brain parenchyma in vivo. Science 308: 1314-1318. CrossRef Medline

Parkhurst CN, Yang G, Ninan I, Savas JN, Yates JR 3rd, Lafaille JJ, Hempstead BL, Littman DR, Gan WB (2013) Microglia promote learningdependent synapse formation through brain-derived neurotrophic factor. Cell 155:1596-1609. CrossRef Medline

Prinz M, Priller J (2014) Microglia and brain macrophages in the molecular age: from origin to neuropsychiatric disease. Nat Rev Neurosci 15:300312. CrossRef Medline

Qu J, Jakobs TC (2013) The time course of gene expression during reactive gliosis in the optic nerve. PLoS One 8:e67094. CrossRef Medline

Rice RA, Spangenberg EE, Yamate-Morgan H, Lee RJ, Arora RP, Hernandez MX, Tenner AJ, West BL, Green KN (2015) Elimination of microglia improves functional outcomes following extensive neuronal loss in the hippocampus. J Neurosci 35:9977-9989. CrossRef Medline

Silver J, Miller JH (2004) Regeneration beyond the glial scar. Nat Rev Neurosci 5:146-156. CrossRef Medline

Spangenberg EE, Lee RJ, Najafi AR, Rice RA, Elmore MR, Blurton-Jones M, West BL, Green KN (2016) Eliminating microglia in Alzheimer's mice prevents neuronal loss without modulating amyloid-beta pathology. Brain 139:1265-1281. CrossRef Medline

Streit WJ (2002) Microglia as neuroprotective, immunocompetent cells of the CNS. Glia 40:133-139. CrossRef Medline

Szalay G, Martinecz B, Lénárt N, Környei Z, Orsolits B, Judák L, Császár E, Fekete R, West BL, Katona G, Rózsa B, Dénes Á (2016) Microglia protect against brain injury and their selective elimination dysregulates neuronal network activity after stroke. Nat Commun 7:11499. CrossRef Medline

Tanaka T, Ueno M, Yamashita T (2009) Engulfment of axon debris by microglia requires p38 MAPK activity. J Biol Chem 284:21626-21636. CrossRef Medline

Thanos S, Fischer D, Pavlidis M, Heiduschka P, Bodeutsch N (2000) Glioanatomy assessed by cell-cell interactions and phagocytotic labelling. J Neurosci Methods 103:39-50. CrossRef Medline

van Rooijen N, Sanders A, van den Berg TK (1996) Apoptosis of macrophages induced by liposome-mediated intracellular delivery of clodronate and propamidine. J Immunol Methods 193:93-99. CrossRef Medline

Waisman A, Ginhoux F, Greter M, Bruttger J (2015) Homeostasis of microglia in the adult brain: review of novel microglia depletion systems. Trends Immunol 36:625-636. CrossRef Medline

Wang X, Zhao L, Zhang J, Fariss RN, Ma W, Kretschmer F, Wang M, Qian HH, Badea TC, Diamond JS, Gan WB, Roger JE, Wong WT (2016) Requirement for microglia for the maintenance of synaptic function and integrity in the mature retina. J Neurosci 36:2827-2842. CrossRef Medline

Wohl SG, Schmeer CW, Witte OW, Isenmann S (2010) Proliferative response of microglia and macrophages in the adult mouse eye after optic nerve lesion. Invest Ophthalmol Vis Sci 51:2686-2696. CrossRef Medline

Yin Y, Cui Q, Li Y, Irwin N, Fischer D, Harvey AR, Benowitz LI (2003) Macrophage-derived factors stimulate optic nerve regeneration. J Neurosci 23:2284-2293. Medline 